\title{
Establishing an infrastructure to support the development and delivery of clinical research in patients with kidney disease
}

\author{
Author: The UK Kidney Research Consortium ${ }^{\mathrm{A}}$
}

\begin{abstract}
The UK Kidney Research Consortium (UKKRC) was established in $\mathbf{2 0 0 7}$ to promote clinical research in adults and children affected by kidney disease. Clinical study groups (CSGs) are the core subgroups of UKKRC. The aim of the CSGs is to generate a portfolio of clinical studies that can and should be undertaken in the UK. Since 2007 the CSGs have helped develop and secure funding for 13 studies to a total value of $£ 13,443,648$. Funders include Kidney Research UK, Medical Research Council, British Heart Foundation and National Institute of Health Research (NIHR). The studies address the full translational pathway. UKKRC is thus a unique structure that dovetails with the NIHR Renal Disorders Specialty Group to generate and deliver a portfolio of high-quality renal studies.
\end{abstract}

KEYWORDS: Kidney disease, rare diseases, clinical research, research networks, patient and public involvement

\section{Development of the Clinical Research Network}

In 2003 the Academy of Medical Sciences published a report titled Strengthening clinical research ${ }^{1}$ which documented a 'substantial gulf between basic discoveries and converting such discoveries into innovations that directly benefit patients or prevent disease' in the UK. Two areas felt to be in particular need of attention were experimental medicine and large-scale clinical trials. Progress in these areas had been hindered by a lack of appropriate facilities and infrastructure, a lack of appropriately trained clinical scientists and a career structure to support them, inadequate funding support for experimental medicine and all types of clinical trials, a failure to use the opportunity provided by the NHS to generate high-quality clinical data for such studies and increasingly complex and bureaucratic legal and ethical frameworks in the UK and EU. Subsequently, the Department of Health published Best research for best health ${ }^{2}$ outlining a new national health research strategy that established five goals to address these failings. These were to establish the NHS as an internationally recognised centre of research excellence, to attract, develop and retain the best research professionals to conduct people-based research, to

Author: AKidney Research UK, Peterborough, UK commission research focused on improving health and social care, to manage our knowledge resources and to act as sound guardians of public money for public good. To establish the NHS as a centre of research excellence the National Institute of Health Research (NIHR) was created. A key part of the NIHR structure is the Clinical Research Network (CRN). Initially this comprised topic-specific CRNs, including cancer, mental health, stroke, diabetes, dementia and neurodegenerative, medicines for children and primary care. The first topic specific network was the National Cancer Research Network, established in 2001. The network rapidly led to increased patient participation with a four-fold increase in recruitment into high-quality studies between 2001 and 2010. ${ }^{3}$ The success of the cancer network led the Department of Health to invest in further networks and the success of these in turn ${ }^{4}$ resulted in the establishment in England of the Comprehensive Local Research Networks (CLRNs) in 2007. The CLRNs provided support for the delivery of studies including specialities not already covered by the topic-specific networks. ${ }^{5}$ Speciality groups were established both locally and nationally to facilitate this, including a renal speciality group with the primary aim of managing a high-quality portfolio of clinical research studies. However, distinct from the topic-specific networks, the CLRNs and speciality groups did not have a mandate for developing new studies (portfolio generation). Subsequently the topic networks and CLRNs were combined in 2014 into a single CRN (the NIHR CRN) but with maintenance of the renal disorders speciality group within the new structures. This reorganisation saw the 25 CLRNs consolidated into 15 local CRNs (LCRNs), with development of a divisional structure facilitating better sharing of resources, a leaner management structure and optimisation of recruitment. Hence, renal disorders now shares division 2 with diabetes, cardiovascular, stroke and endocrine/ metabolic disorders. The renal disorders specialty group is thus a component of the NIHR CRN.

\section{Establishment of the UK Kidney Research Consortium}

The need to provide a structure to facilitate the best research, foster translational research and promote excellence in kidney research was recognised by the renal community. An inclusive consortium (the UK Kidney Research Consortium (UKKRC)) was therefore established in 2007 comprising key stakeholders in renal research from across the UK. The current membership of the consortium is shown in Box 1. The consortium is hosted 


\section{Box 1. Membership of the UKKRC.}

Chairs of the CSGs

Local leads of the CRN Renal Disorders Speciality Groups

Chair of the National CRN Renal Disorders Speciality Group

President, Renal Association

President-elect, Renal Association

Academic vice president, Renal Association

Chair of Research Committee, Renal Association

Chair, Kidney Research UK

Chair, Kidney Research UK Research Strategy Committee

Chief executive, Kidney Research UK

Development director, Kidney Research UK

Head of Research Operations, Kidney Research UK

Medical director, UK Renal Registry

Representative, Clinical Research Collaboration Cymru

Representative, Northern Ireland Research Network

Representative, Scottish CRN

Representatives, Patient and Public Involvement

Representative, Renal Specialist Registrar Club

President, British Renal Society

Research chair, British Renal Society

National clinical director for renal disease

Chairman, Rare Diseases Committee, Renal Association

President, British Association for Paediatric Nephrology

Chairman, National Kidney Federation

CSG = clinical study group; $C R N=$ Clinical Research Network; UKKRC = UK

Kidney Research Consortium.

\section{Box 2. Clinical study groups.}

\author{
Acute kidney injury \\ Anaemia \\ Bone/phosphate \\ Cardio-renal \\ Chronic kidney disease \\ Cystic diseases \\ Exercise \\ Glomerulonephritis and vasculitis \\ Haemodialysis \\ Paediatrics \\ Peritoneal dialysis \\ Transplantation
}

by the Renal Association, the British Renal Society and Kidney Research UK, with the chair rotating biennially. The key core subgroups of UKKRC are the 12 clinical study groups (CSGs) listed in Box 2. The membership and reporting lines of UKKRC are shown in Fig 1; this includes the NIHR CRN represented by the chair of the national renal disorders speciality group. It was agreed that membership of the CSGs should be inclusive with representation from the multiprofessional team and wherever possible include trainees and patient/carer representatives. The CSGs are responsible for identifying areas where there is a clear need for more evidence, designing studies to address these areas and developing appropriate grant applications. Thus UKKRC fulfils the portfolio-generating role not covered by the CLRNs or in their successor the NIHR CRN. So far this role has resulted in the development and successful funding of

\section{Renal Association, British Renal Society and Kidney Research UK}

\begin{tabular}{|c|c|c|}
\hline \multicolumn{3}{|c|}{ UKKRC } \\
\hline Renal Association & British Renal Society & Kidney Research UK \\
\hline National Kidney Federation & Renal Association Rare Disease Committee & UK Renal Registry \\
\hline Clinical Research Collaboration Cymru & Northern Ireland Research Network & Scottish Clinical Research Network \\
\hline NIHR Clinical Research Network & NHS England & Renal Specialist Registrar Club \\
\hline \multicolumn{3}{|c|}{ British Association for Paediatric Nephrology } \\
\hline \multicolumn{3}{|c|}{ CSGs } \\
\hline Acute kidney injury & Anaemia & Bone/phosphate \\
\hline Cardio-renal & Chronic kidney disease & Cystic diseases \\
\hline Exercise & Glomerulonephritis and vasculitis & Haemodialysis \\
\hline Paediatrics & Peritoneal dialysis & Transplantation \\
\hline
\end{tabular}

Fig 1. Organogram showing the membership and reporting lines of UKKRC. CGCs = clinical study groups; NIHR = National Institute for Health Research; UKKRC = UK Kidney Research Consortium. 
13 studies to a total value of $13,443,648 \mathfrak{E}$. In total, 7 have been funded by NIHR, 3 by Kidney Research UK, 2 by the British Heart Foundation and 1 by the Medical Research Council. A list of these studies is shown in Table 1.
While the delivery of NIHR portfolio studies is primarily the remit of the NIHR CRN and its renal disorders speciality group, CSGs have also assumed responsibility for identifying and then supporting studies that are not recruiting to time and

Table 1. Studies developed by the CSGs which have been funded.

\begin{tabular}{|c|c|c|c|c|c|}
\hline $\begin{array}{l}\text { Year of } \\
\text { application }\end{array}$ & $\begin{array}{l}\text { Funding } \\
\text { body }\end{array}$ & Title of application & Acronym & $\begin{array}{l}\text { Value of } \\
\text { Grant }\end{array}$ & $\begin{array}{l}\text { NIHR portfolio } \\
\text { number }\end{array}$ \\
\hline 2013 & $\begin{array}{l}\text { Kidney } \\
\text { Research UK }\end{array}$ & $\begin{array}{l}\text { UK multicentre open-label RCT of IV iron therapy in } \\
\text { incident haemodialysis patients }\end{array}$ & PIVOTAL & $£ 2,500,000$ & 15250 \\
\hline 2014 & $\begin{array}{l}\text { Kidney } \\
\text { Research UK }\end{array}$ & $\begin{array}{l}\text { Exploratory multicentre prospective double-blinded } \\
\text { randomised controlled pilot study of the effect of } \\
\text { intravenous iron supplementation (Monofer }{ }^{\circledR} \text { ) in iron } \\
\text { deficient but not anaemic patients with chronic kidney } \\
\text { disease stages 3b or worse on functional status and } \\
\text { cardiac structure and function }\end{array}$ & & $£ 184,000$ & \\
\hline 2013 & $\mathrm{BHF}$ & $\begin{array}{l}\text { PD-HF: a trial of peritoneal dialysis for patients with } \\
\text { advanced heart failure and stage } 3-4 \text { chronic kidney } \\
\text { disease }\end{array}$ & PD-HF & $£ 251,261$ & 18071 \\
\hline 2013 & NIHR HTA & $\begin{array}{l}\text { Accuracy of glomerular filtration rate estimation } \\
\text { using creatinine and cystatin } C \text { and albuminuria for } \\
\text { monitoring disease progression in patients with stage } \\
3 \text { chronic kidney disease: an observational study in a } \\
\text { multi-ethnic population }\end{array}$ & eGFR-C & $£ 2,033,742.80$ & 15268 \\
\hline 2013 & $\begin{array}{l}\text { NIHR/MRC } \\
\text { EME }\end{array}$ & $\begin{array}{l}\text { Multicentre phase IV RCT of angiotensin-converting } \\
\text { enzyme inhibitor/angiotensin receptor blocker } \\
\text { withdrawal in chronic kidney disease - STOP-ACEi- } \\
\text { STUDY (SAS) (2013-2017) }\end{array}$ & STOP-ACEi & $£ 1,656,752$ & 15908 \\
\hline 2013 & NIHR HTA & $\begin{array}{l}\text { PrEscription of intraDialytic exercise to improve quAlity } \\
\text { of Life }\end{array}$ & PEDAL & $£ 2,100,000$ & 17726 \\
\hline 2011 & NIHR HTA & $\begin{array}{l}\text { Long-term tapering verses standard prednisolone } \\
\text { (steroid) therapy for the treatment of the initial episode } \\
\text { of childhood nephrotic syndrome: national multicentre } \\
\text { randomised double blind trial }\end{array}$ & PREDNOS & $£ 734,696$ & 9617 \\
\hline 2012 & NIHR HTA & $\begin{array}{l}\text { Short course daily prednisolone therapy at the time } \\
\text { of upper respiratory tract infection in children with } \\
\text { relapsing steroid sensitive nephrotic syndrome }\end{array}$ & PREDNOS 2 & $£ 823,370$ & 13410 \\
\hline 2013 & $\begin{array}{l}\text { Kidney } \\
\text { Research UK }\end{array}$ & $\begin{array}{l}\text { The effects of HDF versus conventional haemodialysis } \\
\text { on growth and cardiovascular markers in children } 3 \mathrm{H} \\
\text { (HDF, hearts and height) study }\end{array}$ & $3 \mathrm{H}$ & $£ 199,938$ & 15145 \\
\hline 2012 & $\mathrm{BHF}$ & $\begin{array}{l}\text { The Hypertension Optimal Treatment in Children With } \\
\text { Chronic Kidney Disease Study - a randomised trial to } \\
\text { compare effects of aggressive versus standard targets in } \\
\text { blood pressure on target organ damage in children with } \\
\text { chronic kidney disease }\end{array}$ & HOT-KID & $£ 247,487$ & 12925 \\
\hline 2014 & NIHR RfPB & $\begin{array}{l}\text { Optimising early dialysis catheter function - the UK } \\
\text { peritoneal dialysis outcomes and practice patterns study }\end{array}$ & & $£ 349,989$ & 17940 \\
\hline 2011 & NIHR RfPB & $\begin{array}{l}\text { A validated competitive risk model that will inform a } \\
\text { decision aid for peritoneal dialysis patients deciding } \\
\text { whether to switch modality to avoid developing } \\
\text { encapsulating peritoneal sclerosis }\end{array}$ & PD-CRAFT & $£ 246,722$ & 12482 \\
\hline 2011 & MRC & $\begin{array}{l}\text { A double blind randomised controlled investigation into } \\
\text { the efficacy of Mirococept (APT070) for preventing } \\
\text { ischaemia-reperfusion injury in the kidney allograft }\end{array}$ & EMPIRIKAL & $£ 2,115,690$ & 16181 \\
\hline
\end{tabular}


Box 3. Rare disease groups.

Alport syndrome

Autosomal recessive polcystic kidney disease

Adenine phosphoribosyltransferase deficiency

Atypical haemolytic uraemic syndrome

Cystinosis

Cystinuria

Dent disease and Lowe syndrome

Familial urate associated nephropathy (uromudulin associated nephropathy, hyperuricaemic nephropathy and medullary cystic kidney disease)

Hepatocyte nuclear factor-1 beta

Shiga toxin-associated hemolytic-uremic syndrome

Hyperoxaluria (primary hyperoxaluria, oxalosis)

Hypokalaemic alkaloses (Bartter, EAST, Gitelman and Liddle syndromes)

Membranous nephropathy

Membranoproliferative glomerulonephritis, dense deposit disease

Nephrotic syndrome (steroid resistant, congenital, associated with primary focal segmental glomerulosclerosis)

Pregnancy in chronic kidney disease

Pure red cell aplasia

Vasculitis

target. This strengthens the synergy between UKKRC and the renal disorders speciality group. To promote this synergy the two organisations meet 'back-to-back' on the same day twice a year and many key researchers have roles in both groups. We are not aware of other specialty groups where there is a similar synergistic relationship.

As can be seen from Box 1, UKKRC has representatives from the research networks of Scotland, Northern Ireland and Wales. Studies that are developed by the CSGs are open to patients in all of the countries of the UK.

\section{Establishment of an infrastructure for the study of rare renal diseases}

In 2010 the Renal Association and the British Association for Paediatric Nephrology published Rare kidney diseases: an integrated strategy for patients in the UK. ${ }^{6}$ Implementation of this strategy required the introduction of diseasespecific working groups, development of care pathways and introduction of a UK registry for rare kidney diseases. Funded by Kidney Research UK and the British Kidney Patient Association, disease-specific working groups (rare disease groups (RDGs)) have now been established for 12 diseases and are listed in Box 3. Like the UKKRC, CSG membership of the RDGs is inclusive with representation from the multiprofessional team, trainees and patient/carer representatives. There is, however, a greater emphasis on patient/carer involvement with many of the groups organising information days. Out of these, independent patient-family support groups, such as those for atypical haemolytic uraemic syndrome (aHUSUK) and membranoproliferative glomerulonephritis/dense deposit disease (the membranoproliferative glomerulonephritis (MPGN)/dense deposit disease (DDD) support group), have evolved. The RDGs are responsible for providing information about their respective diseases for both clinicians and patients. This information is available at www.rarenal.org and includes care pathways. A registry for each of these diseases has been established at www. renalradar.org and so far information from over 1,500 patients has been entered. The RDGs, like the CSGs, have a substantial role in both the generation of new studies and their delivery. For example, both the steroid resistant nephrotic syndrome (SRNS) and MPGN/DDD groups have developed NIHR portfolio studies. These are 'RaDaR; the SRNS Study' and the 'National Study of Membranoproliferative Glomerulonephritis'. The target for recruitment to both has been exceeded. The RDGs therefore sit alongside the CSGs within the UKKRC and fulfil a role in both generation and delivery of portfolio studies.

\section{Patient, carer and public involvement and engagement in UKKRC}

The importance of patient, carer and public involvement and engagement (PCPIE) in the design and delivery of studies has been emphasised by a recent report from the Mental Health Research Network showing an association between the extent of patient involvement in studies and recruitment to target. ${ }^{7}$ PCPIE representation within the UKKRC is achieved at multiple levels. Membership of the UKKRC includes patients and carers proposed by Kidney Research UK. These include both trustees and members of the charity's lay advisory committee. In addition the chair of the National Kidney Federation is a member of UKKRC. There are also patient/carer representatives within most of the CSGs and RDGs.

\section{Industry and UKKRC}

A priority for the NIHR CRN is to help the life-sciences industry undertake high-quality research within the NHS. This includes support for undertaking feasibility, set-up and performance management of studies. This initiative has been very successful with industry studies adopted to the NIHR portfolio accounting for over $50 \%$ of all commercial phase II-IV studies. Through the CSGs, UKKRC has provided extra support for the life-sciences industry by identifying areas where there is a clear need for high-quality studies which would best be provided by a collaboration between a CSG (or multiple CSGs) and industry. A good example of this is the PIVOTAL study (Proactive IV irOn Therapy in haemodiALysis patients). One of the key questions the anaemia CSG identified as a high priority concerned what the optimal dose of intravenous iron should be in haemodialysis patients. This was because publication of several randomised controlled trials (RCTs) of erythropoiesis stimulating agents (ESAs) in chronic kidney disease had shown harm associated with high doses, and consequently intravenous iron dosing had increased corresponding with reduced ESA use. It seemed appropriate to seek an industry partner for such a study and the pharmaceutical companies that market intravenous iron were approached. Vifor Pharmaceuticals markets two IV 
iron preparations, Venofer ${ }^{\circledR}$ and Ferinject ${ }^{\circledR}$, and responded enthusiastically, providing an unrestricted award to Kidney Research UK that was sufficient to enable the study to be undertaken. The company is also providing all the iron for the study for free. Using the governance structures of Kidney Research UK, including full external peer review, a protocol for an open-label RCT comparing a high dose of intravenous iron with a standard low dose was developed. With a sample size of 2,080, the study started in September 2013 and is recruiting well. This model of trial development benefits both the pharmaceutical industry and the renal research community. The funding of this large RCT is extremely modest at

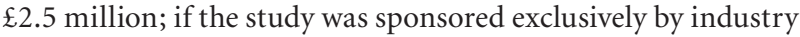
it would cost significantly more than this. Performing this trial with such limited resources relies on the infrastructure support of the NIHR LCRNs, which had been geared up to anticipate PIVOTAL in advance of its inception.

One of the main impediments to industry bringing forward new medicines for renal patients is the lack of validated end points and patient reported outcomes. In the future, UKKRC could extend its role to work with regulatory agencies and industry to agree how new medicines could be supported through the development pathway.

\section{UKKRC and the translational gaps}

The Cooksey review ${ }^{8}$ identified two key gaps in the translation of health research - 'translating ideas from basic and clinical research into the development of new products and approaches to treatment of disease and illness' and 'implementing those new products and approaches into clinical practice'. Table 1 shows that the CSGs have successfully developed studies (such as the EMPIRIKAL study) within the first translational gap. Cooksey identified four organisations involved in addressing the second translational gap - the Health Technology Assessment (HTA) programme, the Service Delivery and Organisation programme, the National Institute for Health and Care Excellence and NHS Connecting for Health. Table 1 shows that the CSGs have developed four studies which have been funded by the HTA. From this it is apparent that the UKKRC has successfully covered the full spectrum of the pathway for translation of health research into healthcare improvement.

\section{A national strategy for renal research}

In October 2013, Kidney health: delivering excellence, a report on kidney health, was published under the auspices of Kidney Research UK, the Renal Association, the British Kidney Patient Association, the British Renal Society, the British Association for Paediatric Nephrology and the British Transplantation Society. ${ }^{9}$ This report documents the future ambitions of the renal community for the kidney care pathway. Research is an integral part of this pathway and the stated ambition was that 'a research strategy for kidney disease is developed, supported by the funding required to design and conduct high quality studies, and used to further understanding of the mechanisms of disease, and improve healthcare quality and outcomes'. The renal community have responded to meeting this ambition.
Coordinated by the UKKRC, a steering group has been established with representation from the renal community to provide a roadmap leading to the publication of a national renal research strategy in 2015.

\section{Conclusion}

The establishment of the UKKRC in parallel with the initiation of the renal speciality group within the CLRN, and more recently the renal disorders speciality group within the NIHR $\mathrm{CRN}$, has provided a unique structure that optimises the potential of the renal research community in the UK to develop and deliver high-quality multicentre, multidisciplinary clinical studies. Whether this potential is realised in future years will be judged on factors such as metrics for recruitment to time and target, the generation of evidence relevant to clinical practice and changes in clinical practice that improve outcomes for patients. The development of a national renal research strategy will ensure that the development of clinical studies meets the priorities of the renal community.

\section{References}

1 The Academy of Medical Sciences. Strengthening clinical research. London: AoMS, 2003. Available online at www.acmedsci.ac.uk/ viewFile/publicationDownloads/pscr.pdf [Accessed 28 July 2015].

2 Department of Health. Best research for best health: a new national health research strategy. London: DoH, 2006. Available online at www.gov.uk/government/uploads/system/uploads/attachment_data/ file/136578/dh_4127152.pdf [Accessed 28 July 2015].

3 Stead M, Cameron D, Lester N et al. Strengthening clinical cancer research in the United Kingdom. Br J Cancer 2011;104:1529-34.

4 Rose AC, Van't Hoff W, Beresford MW, Tansey SP. NIHR Medicines for Children Research Network: improving children's health through clinical research. Expert Rev Clin Pharmacol 2013;6:581-7.

5 Evans TW, Gower J, Neilson J et al. Report of a Royal College of Physicians and National Institute for Health Research workshop developing research capacity to ensure successful study development and delivery. Clin Med 2013;13:431-3.

6 The Renal Association and British Association for Paediatric Nephrology. Rare kidney diseases: an integrated strategy for patients in the UK. Petersfield: Renal Association and British Association for Paediatric Nephrology, 2010. Available online at http://rarerenal.org/ wp-content/uploads/2013/09/UK_Rare_Kidney_Disease_Strategy_ APRIL_2010.sflb_.pdf [Accessed 28 July 2015].

7 Ennis L, Wykes T. Impact of patient involvement in mental health research: longitudinal study. Br J Psychiatry 2013;203:381-6.

8 Cooksey D. A review of UK health research funding. Norwich: HMSO, 2006. Available online at www.gov.uk/government/uploads/system/ uploads/attachment_data/file/228984/0118404881.pdf [Accessed 28 July 2015].

9 Kidney Health. Kidney health: delivering excellence. Kidney Health, 2013. Available online at www.britishrenal.org/BritishRenalSociety/ files/c8/c8dc5fcd-bf0c-4179-aa76-36549146fbbd.pdf [Accessed 28 July 2015].

Address for correspondence: UK Kidney Research Consortium, Kidney Research UK, Nene Hall, Lynch Wood Park,

Peterborough PE2 6FZ, UK.

Email: UKKRC@kidneyresearchuk.org 